\title{
Wide variation in caffeine discontinuation timing in premature infants
}

\author{
Dabin $\mathrm{Ji}^{1} \cdot$ P. Brian Smith ${ }^{2,3} \cdot$ Reese H. Clark ${ }^{4} \cdot$ Kanecia O. Zimmerman ${ }^{2} \cdot$ Matthew Laughon $^{5} \cdot$ Lawrence Ku$^{2}$. \\ Rachel G. Greenberg $\mathbb{1}^{2,3}$
}

Received: 2 August 2019 / Revised: 29 October 2019 / Accepted: 13 November 2019 / Published online: 22 November 2019

(c) The Author(s), under exclusive licence to Springer Nature America, Inc. 2019

\begin{abstract}
Objective To assess site variability and concomitant respiratory support related to the timing of caffeine discontinuation, and compare clinical characteristics of infants who discontinued caffeine before vs. within the last week of hospitalization.

Study design Cohort study of 81,110 infants $<35$ weeks gestational age and $<1500 \mathrm{~g}$ birth weight discharged from 304 neonatal intensive care units from 2001-2016.

Results The mean postmenstrual age at caffeine discontinuation ranged from 32 to 37 weeks among sites. Respiratory support at the time of discontinuation was common, but variable, with $0-57 \%$ of infants receiving positive airway pressure at caffeine discontinuation by site. Infants who discontinued caffeine within the last week of hospitalization had longer total duration of caffeine, but were discharged from the hospital at an earlier postmenstrual age.

Conclusion There was substantial variability among sites in the timing of caffeine discontinuation before discharge and respiratory support at the time of caffeine discontinuation.
\end{abstract}

\section{Introduction}

Apnea of prematurity is a common disorder in premature infants; severe cases are associated with the increased risk of death and neurodevelopmental impairment [1-5]. Caffeine citrate is the mainstay pharmacologic treatment of apnea of prematurity and reduces the frequency of apnea and intermittent hypoxemia, facilitates extubation from mechanical ventilation, and is associated with reducing the incidence of bronchopulmonary dysplasia (BPD) in premature infants [4, 6-10].

Rachel G. Greenberg

rachel.greenberg@duke.edu

1 Mercer University School of Medicine, Savannah, GA, USA

2 Department of Pediatrics, Duke University, Durham, NC, USA

3 Duke Clinical Research Institute, Durham, NC, USA

4 Pediatrix Medical Group, Sunrise, FL, USA

5 Department of Pediatrics, The University of North Carolina at Chapel Hill, Chapel Hill, NC, USA
While the benefits of caffeine therapy are well studied, the appropriate timing of discontinuation relative to infant discharge from the hospital is unknown. Neonatologists typically observe infants for the completion of an "event-free" period after the discontinuation of caffeine therapy as a prerequisite for discharge;[11] however, no consensus among clinicians currently exists in regards to what length of apnea-free period is adequate enough to determine safe discharge [12]. Notably, some infants are discharged home on caffeine as a means of achieving earlier hospital discharge [13, 14]. Neonatologists must weigh the risks of early caffeine discontinuation (need for restart of therapy, respiratory compromise, and need for escalation of support) with those of later caffeine discontinuation (possible prolonged hospital stay and increased costs) in order to discontinue caffeine at an optimal time [15].

This study assessed site variability and concomitant respiratory support related to the timing of caffeine discontinuation, as well as clinical characteristics of infants who discontinued caffeine prior to the last week of hospitalization compared with infants who discontinued caffeine within the last week of hospitalization. 


\section{Methods}

\section{Patient selection}

The source of data for our study was the Pediatrix Medical Group Clinical Data Warehouse. This data warehouse captures data collected in the shared electronic health record of 304 neonatal intensive care units (NICUs) in North America managed by the Pediatrix Medical Group. We extracted data from admission notes, daily progress notes, and discharge summaries, including information on the demographics and characteristics of all admitted infants [16].

In this study, we identified infants who were discharged from NICUs managed by the Pediatrix Medical Group between the years of 2001 and 2016. We included all inborn infants who met the following criteria: gestational age $<35$ weeks and birth weight $<1500 \mathrm{~g}$. We excluded infants who did not survive to discharge, were never treated with caffeine therapy, were transferred prior to caffeine discontinuation and discharge, or in whom the day of caffeine discontinuation was unknown. Infant demographics and clinical characteristics of interest included birth weight; gender; race; gestational age; small-for-gestational status; surfactant use; appearance, pulse, grimace, activity, and respiration (APGAR) score at $5 \mathrm{~min}$; mode of delivery; and prenatal steroid exposure. The Duke University Institutional Review Board gave approval for the conduct of this study and granted a waiver of written informed consent.

\section{Definitions}

We defined postmenstrual age (PMA) as the sum of the gestational age at birth and the chronological age in weeks. Respiratory support on the last day of caffeine therapy included the use of supplemental oxygen and positive airway pressure (high flow nasal cannula, continuous positive airway pressure, or ventilator support). Small-for-gestational age was determined by Olsen definitions [17]. We defined infants $<32$ weeks gestational age as having BPD if they received respiratory support or supplemental oxygen continuously from a corrected gestational age of $360 / 7$ weeks to 36 $6 / 7$ weeks [18]. We defined infants $\geq 32$ weeks gestational age as having BPD if they received respiratory support or supplemental oxygen continuously from a postnatal age of 28-34 days [18]. Infants were considered discharged on caffeine therapy if they were receiving caffeine therapy on the day of or the day before discharge.

\section{Statistical analysis}

We used summary statistics, including median, 25th-75th percentile, counts, and proportions to describe continuous and categorical variables. We divided the patient population into two groups: (1) infants who discontinued caffeine therapy before the last week of hospitalization; and (2) infants who discontinued caffeine within the last week of hospitalization. The last week of hospitalization was chosen as a comparison time point because of the long half-life of caffeine and previous recommendations to monitor infants for a period of 7 days free of apnea before discharge [12, 19]. We compared demographic and clinical characteristics between these groups. For the two groups, we evaluated and compared the PMA at first administration of caffeine, postnatal age at first administration of caffeine, PMA at discontinuation of caffeine, PMA at discharge from hospital, total duration of caffeine, and the presence of BPD at any gestational age. For infants who discontinued caffeine before the last week of hospitalization, we evaluated respiratory support at the time of caffeine discontinuation and the time between caffeine discontinuation and discharge. To compare the variable distribution across groups, we used Fisher's exact test or the chisquare test which where appropriate for categorical variables and the Wilcoxon rank-sum test for continuous variables. Among sites who discharged at least 50 infants throughout the study period, we also compared clinical characteristics (mean postmenstrual age at caffeine discontinuation, mean gestational age, percentage of infants on positive airway pressure, and the ventilator at time of caffeine discontinuation). All analyses were performed using STATA 15.1 (StataCorp, College Station, TX) and assumed a two-sided significance limit of $\alpha=0.05$.

\section{Results}

\section{Patient characteristics}

A total of 81,110 infants were included in the study. Of these 81,110 infants, 5706 (7\%) discontinued caffeine within the last week of hospitalization. Compared with infants who discontinued caffeine within the last week of hospitalization, infants who discontinued caffeine prior to the last week of hospitalization were more likely to have a lower birth weight, earlier gestational age, be small-forgestational age, receive surfactant, receive prenatal steroids, have a lower 5-min APGAR score, and be delivered by cesarean section (Table 1).

\section{Caffeine administration characteristics}

Significant differences were noted for the PMA at first administration of caffeine, the postnatal age at first administration of caffeine, the PMA at discontinuation of caffeine, the PMA at discharge from hospital, and the total duration of caffeine between the two groups (Table 2). 
Table 1 Demographics

\begin{tabular}{|c|c|c|c|}
\hline & $\begin{array}{l}\text { Caffeine discontinued } \\
\text { before last week of } \\
\text { hospitalization } \\
N=75,404\end{array}$ & $\begin{array}{l}\text { Caffeine discontinued } \\
\text { within last week } \\
\text { of hospitalization } \\
N=5706\end{array}$ & $p$ value \\
\hline \multicolumn{4}{|l|}{ Infants } \\
\hline Male $-n(\%)$ & $37,870(50)$ & $2842(50)$ & 0.54 \\
\hline Birth weight (g)—n(\%) & & & $<0.001$ \\
\hline$<750$ & $11,593(15)$ & $461(8)$ & \\
\hline 750-999 & $19,930(26)$ & $1115(20)$ & \\
\hline $1000-1249$ & $22,801(30)$ & $1818(32)$ & \\
\hline $1250-1499$ & $21,080(28)$ & $2312(41)$ & \\
\hline $\begin{array}{l}\text { Gestational age } \\
\text { (weeks)—n (\%) }\end{array}$ & & & $<0.001$ \\
\hline $22-25$ & $11,781(16)$ & $518(9)$ & \\
\hline $26-29$ & $43,316(57)$ & $3275(57)$ & \\
\hline $30-32$ & $19,495(26)$ & $1819(32)$ & \\
\hline$>32$ & $812(1)$ & $94(2)$ & \\
\hline $\mathrm{SGA}-n(\%)$ & $12,866(17)$ & $705(12)$ & $<0.001$ \\
\hline Received surfactant—n(\%) & $49,685(66)$ & $3549(62)$ & $<0.001$ \\
\hline 5-minute APGAR score & & & $<0.001$ \\
\hline $0-3$ & 2979 (4) & $155(3)$ & \\
\hline $4-6$ & $12,299(17)$ & 774 (14) & \\
\hline $7-10$ & $58,493(79)$ & $4687(83)$ & \\
\hline $\begin{array}{l}\text { Cesarean section } \\
\text { delivery- }-n(\%)\end{array}$ & $55,603(74)$ & $4110(73)$ & 0.003 \\
\hline Race $-n(\%)$ & & & $<0.001$ \\
\hline White & $34,675(48)$ & $2853(52)$ & \\
\hline Black & $19,398(27)$ & $1222(22)$ & \\
\hline Hispanic & $14,121(19)$ & 1167 (21) & \\
\hline Other & 4426 (6) & $252(5)$ & \\
\hline Prenatal steroids $-n(\%)$ & $61,309(81)$ & $4475(78)$ & $<0.001$ \\
\hline
\end{tabular}

$P M A$ postmenstrual age, $S G A$ small for gestational age

Infants who discontinued caffeine within the last week of hospitalization had a later PMA at first administration of caffeine (29 weeks [25th-75th percentile: 28-31] vs. 28 weeks; [27-30] $P<0.001)$, a higher postnatal age at first administration of caffeine (2 days [1-6] vs. 1 day [0-4]; $P<0.001)$, a later PMA at discontinuation of caffeine (35 weeks [34-36] vs. 34 weeks [33-35]; $P<$ 0.001 ), and longer total duration of caffeine (40 days [29-53] vs. 37 days [24-51]; $P<0.001)$; however, these infants were discharged from the hospital at an earlier PMA (35 weeks [35-37] vs. 37 weeks [36-39]; $P<0.001$ ) (Table 2). The incidence of BPD was significantly higher in infants who discontinued caffeine prior to the last week of hospitalization (29\%) compared with those who discontinued caffeine within the last week of hospitalization $(14 \%)(<0.001)$ (Table 2).

\section{Respiratory support at the time of caffeine discontinuation}

Use of supplemental oxygen and positive airway pressure was common at the time of caffeine discontinuation in infants who discontinued caffeine prior to the last week of hospitalization with 29,20 , and $3 \%$ of infants receiving supplemental oxygen, positive airway pressure, and ventilator support, respectively (Table 2). Fifty-seven percent of infants were on room air at the time of caffeine discontinuation (Table 2). A total of 2097/75,300 (3\%) of infants increased respiratory support within 2 weeks after discontinuing caffeine (Table 2).

\section{Site variability}

While the overall mean PMA at caffeine discontinuation was relatively stable over time from 2001-2016 among individual sites (Fig. 1a), the mean PMA at caffeine discontinuation varied from 32 to 37 weeks (Fig. 2a) between sites. Mean PMA at caffeine discontinuation among sites did not appear to correlate with the mean gestational age of infants at sites (Fig. 2b). In addition, the percentage of infants in whom caffeine was discontinued within the last week of hospitalization decreased over time from 2001-2016, gradually declining from $14 \%$ in 2001 to $4 \%$ in 2016 (Fig. 1b). The percentage of infants on respiratory support at the time of caffeine discontinuation varied among all sites, ranging from 0 to $57 \%$ of infants on positive airway pressure (Fig. 2c) and 0 to $13 \%$ of infants on ventilator support at caffeine discontinuation (Fig. 2d).

\section{Discussion}

Our study reveals variability in the use and discontinuation of caffeine therapy in infants with apnea of prematurity. As expected, PMA at time of caffeine initiation varied across sites, as different sites care for different gestational age populations, and caffeine is often initiated soon after birth. More surprisingly, PMA at the time of caffeine discontinuation ranged from 32 to 37 weeks across sites and did not appear to correlate with the mean gestational age at the site. Also, our study demonstrated a wide range among sites in the percentage of infants in whom caffeine was discontinued during the last week of hospitalization, varying from 0 to $50 \%$, which indicates that there are evident practice differences in how long clinicians watch infants who are off caffeine prior to discharge. While we found that discontinuation of caffeine in the last week of hospitalization occurred more commonly in larger and less premature infants, $28 \%$ of infants who discontinued caffeine in the last week of hospitalization were $<1000 \mathrm{~g}$. In addition, the use of supplemental oxygen and positive airway pressure was common at the time caffeine was discontinued. Our data demonstrate that there is a need to better define when caffeine can be safely discontinued.

Standardizing caffeine therapy comes with challenges, since discontinuing caffeine therapy too soon increases the risk of recurrent problems with apnea and the need for increased respiratory support. On the other hand, by 
Table 2 Caffeine therapy characteristics and outcomes

\begin{tabular}{|c|c|c|c|}
\hline & $\begin{array}{l}\text { Infants who discontinued } \\
\text { caffeine before last week } \\
\text { of hospitalization } \\
N=75,404\end{array}$ & $\begin{array}{l}\text { Infants who discontinued } \\
\text { caffeine within last week } \\
\text { of hospitalization } \\
N=5706\end{array}$ & $P$ value \\
\hline PMA at first administration of caffeine-weeks; median (25th-75th percentile) & $28(27-30)$ & $29(28-31)$ & $<0.001$ \\
\hline Postnatal age at first administration of caffeine-days; median ( 25 th- 75 th percentile) & $1(0-4)$ & $2(1-6)$ & $<0.001$ \\
\hline PMA at discontinuation of caffeine-weeks; median (25th-75th percentile) & $34(33-35)$ & $35(34-36)$ & $<0.001$ \\
\hline PMA at discharge from hospital—weeks; median (25th-75th percentile) & $37(36-39)$ & $35(35-37)$ & $<0.001$ \\
\hline Total duration of caffeine-days; median (25th-75th percentile) & $37(24-51)$ & $40(29-53)$ & $<0.001$ \\
\hline $\begin{array}{l}\text { Time between caffeine discontinuation and discharge—days; median } \\
\text { (25th-75th percentile) }\end{array}$ & $23(15-34)$ & $6(5-7)$ & \\
\hline BPD & $21,759(29)$ & $745(14)$ & $<0.001$ \\
\hline $\begin{array}{l}\text { Maximum daily inspired oxygen at time of discontinuation-\% Median } \\
\text { (25th-75th percentile) }\end{array}$ & $21(21-25)$ & $21(21-21)$ & $<0.001$ \\
\hline $\mathrm{On} \mathrm{FiO}_{2}>21 \%$ at time of caffeine discontinuation- $n(\%)$ & $21,660(29)$ & $759(13)$ & $<0.001$ \\
\hline On HFNC, CPAP, or NIPPV at time of caffeine discontinuation $-n(\%)$ & $15,091(20)$ & $120(2)$ & $<0.001$ \\
\hline Use of ventilator support (CMV or HFV)— $n(\%)$ & $2255(3)$ & $16(0.3)$ & $<0.001$ \\
\hline On room air at time of caffeine discontinuation $-n(\%)$ & $42,863(57)$ & $4702(83)$ & $<0.001$ \\
\hline $\begin{array}{l}\text { Increased support within } 2 \text { weeks after discontinuing } \\
\text { caffeine- } n(\%)\end{array}$ & $2097(3)$ & $11(0.2)$ & $<0.001$ \\
\hline
\end{tabular}

$B P D$ bronchopulmonary dysplasia, $C M V$ continuous mandatory ventilation, $C P A P$ continuous positive airway pressure, $H F N C$ high flow nasal cannula, $H F V$ high frequency ventilation, $N I P P V$ nasal intermittent positive pressure ventilation, $P M A$ postmenstrual age
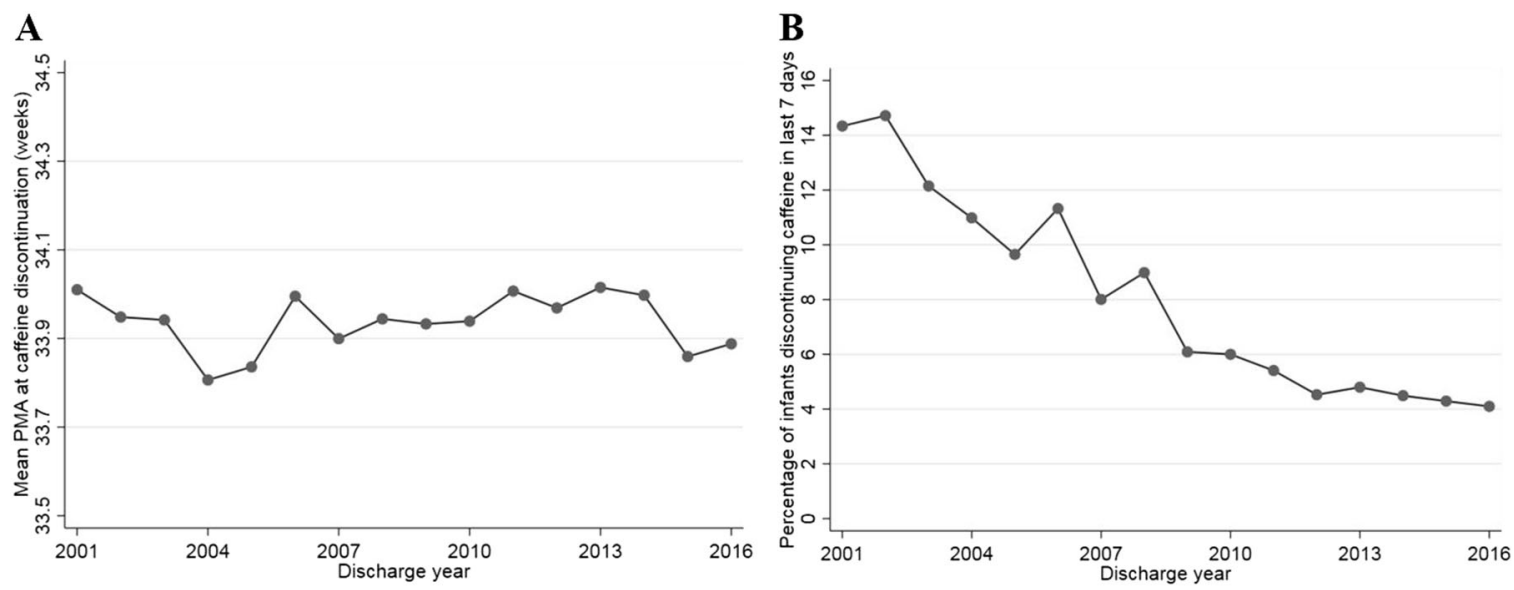

Fig. 1 Caffeine discontinuation over time. a mean PMA at caffeine discontinuation (weeks); and b percentage of infants discontinuing caffeine within last week of hospitalization

delaying the discontinuation of caffeine therapy, physicians run the potential risk of unnecessarily prolonging hospital stays, which adds to the increased burden of health care costs [15]. Standardization of evidence-based interventions by reducing the variance in practice is a key improvement strategy for enhancing health care [20-22].

Caffeine use in premature infants decreases intermittent hypoxia [23], is associated with reducing the incidence of BPD [8, 10], and significantly improves survival without neurodevelopmental disability at a corrected age of 18 months [9, 24]. The mechanism for this neuroprotective effect of caffeine has been thought to be a result of the earlier discontinuation of positive airway pressure in infants on caffeine therapy as compared with those that are not [9].
Although caffeine's neuroprotective benefits are evident, the short- and long-term effects of continued caffeine therapy on the central nervous system are not clearly understood. As a result, neonatologists face the challenge of determining how long to continue caffeine therapy in order to maximize these neuroprotective benefits, including its antioxidant, antiinflammatory, and antiapoptotic properties [25].

Our study was not designed to identify the optimal time for discontinuation of caffeine. Currently, no consensus exists among physicians regarding what length of apneafree period of time is adequate to determine a safe discharge after a significant event [12]. In addition, no national standardization exists for defining a clinically significant event 
$\mathbf{A}$

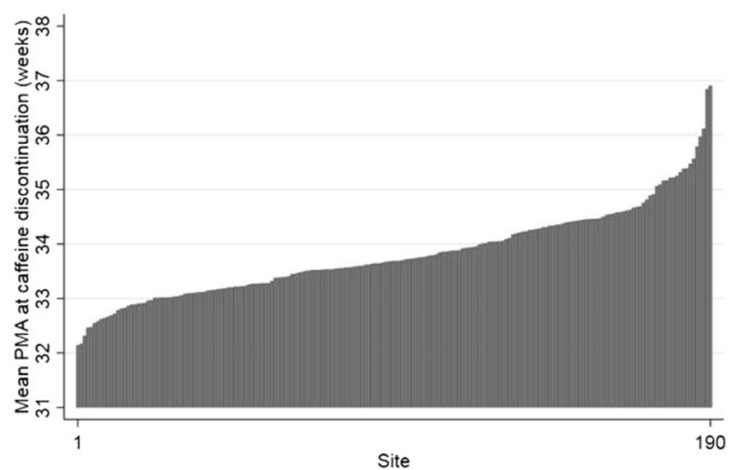

C

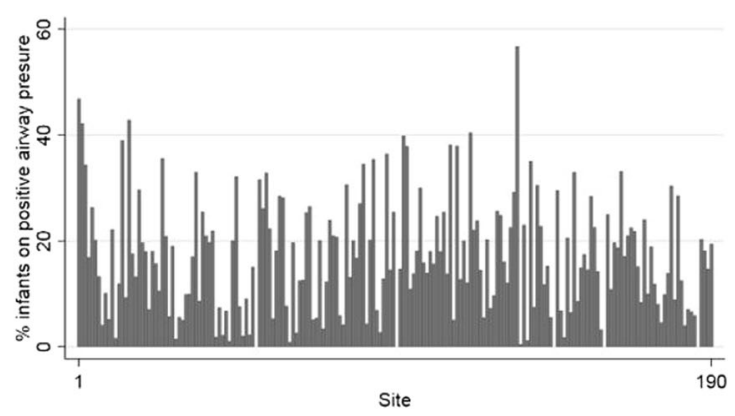

Fig. 2 Caffeine therapy characteristics and respiratory status. Caffeine therapy characteristics and respiratory status at discontinuation according to a mean PMA at caffeine discontinuation (weeks) by site; b mean gestational age (weeks) at first administration of caffeine by

[26, 27]. In 2016, the Committee on Fetus and Newborn 2016 recommended a trial off therapy after an apnea-free period of 5-7 days or 33-34 weeks' PMA, whichever came first, but did not address the length of time an infant should be observed off therapy prior to discharge [19]. Darnall et al. examined the duration of apnea-free period and found that monitoring patients for 7 days identified $75 \%$ of babies who will have apneic spells before discharge; furthermore, this study revealed that infants who have been apnea-free for at least 8 days were less likely to have an apnea event unless they have additional risk factors, including sepsis and surgery [12]. Discharge readiness of premature infants is usually determined by the demonstration of functional maturation and medical stability. Factors contributing to a clinician's decision to discontinue caffeine therapy include the degree of respiratory stability and symptoms suggestive of caffeine-induced toxicity. Physician discomfort, which arises from a lack of evidence from medical literature, may also contribute to the wide variation of practice in response to apnea or bradycardia events [15].

The long half-life of caffeine suggests that some infants who discontinue caffeine within the last 7 days prior to discharge still had caffeine present at the time of discharge, indicating that the level of caffeine may still be therapeutic days after stopping the drug and also after discharge [28].
B

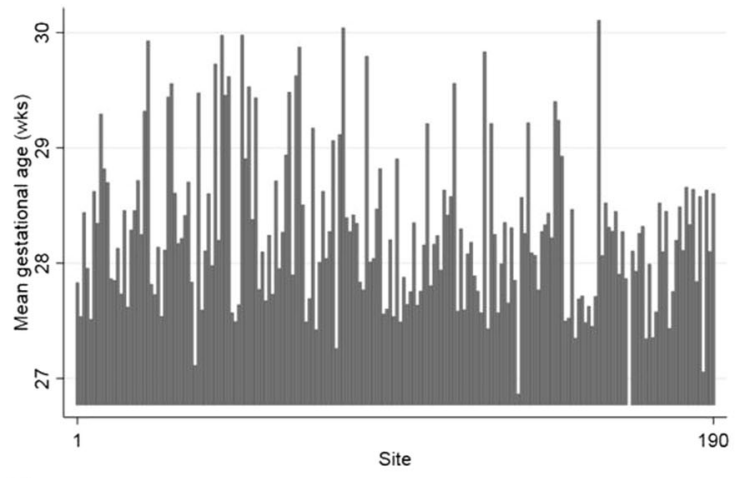

D

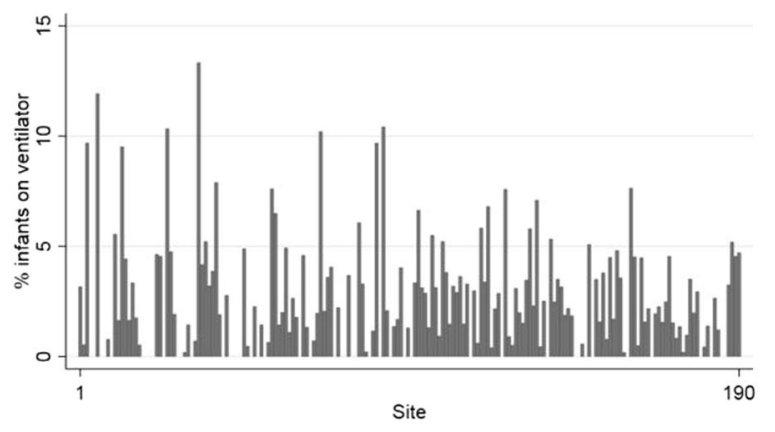

site; c percentage of infants on positive airway pressure at caffeine discontinuation; and d percentage of infants on ventilation at caffeine discontinuation

The long half-life of caffeine also suggests that preterm infants may need to be monitored for recurrence of apnea for more than 5-7 days after discontinuation of caffeine in order to assess an infant's functional status and stability off caffeine prior to discharge. The National Institute of Child Health and Human Development Neonatal Research Network developed a trial to evaluate the effectiveness and safety of continuing caffeine administration throughout the end of hospitalization and after discharge home in moderately preterm infants with resolving apnea of prematurity [29]. This trial, which is currently enrolling, will help to guide appropriate discontinuation timing of caffeine in premature infants.

Our study had several limitations. First, we were not able to evaluate the recurrence of apneic events (prior and after discharge). Second, we were not able to evaluate any additional respiratory support needed or other outcomes after discharge. Third, the variation of timing of when caffeine is stopped may have been due to other patientspecific comorbidities, which were not taken into account. In addition, discharge timing was likely affected by other factors (e.g., growth, feeding, maturity), and the reason for delay in discharge was not available in the dataset. Finally, we were unable to capture any outcomes following hospitalization, including rehospitalization. 
To our knowledge, our study is the first to examine and evaluate the characteristics of infants who discontinued caffeine a week prior to the last week of hospitalization in comparison to those who discontinued caffeine within the last week of hospitalization. Our findings support the need for prospective studies to determine the most appropriate time to discontinue caffeine therapy. Implementation of a standard approach to reduce the wide variation in the timing of caffeine discontinuation in premature infants has the potential to improve the health care and management of premature infants by reducing recurrent apneic events and additional health care costs.

\section{Compliance with ethical standards}

Conflict of interest RGG has received support from industry for research services (https://dcri.org/about-us/conflict-of-interest/). There are no other conflicts of interest to report for any authors.

Publisher's note Springer Nature remains neutral with regard to jurisdictional claims in published maps and institutional affiliations.

\section{References}

1. Barrington K, Finer N. The natural history of the appearance of apnea of prematurity. Pediatr Res. 1991;29:372-5.

2. Eichenwald EC, Blackwell M, Lloyd JS, Tran T, Wilker RE, Richardson DK. Inter-neonatal intensive care unit variation in discharge timing: influence of apnea and feeding management. Pediatrics. 2001;108:928-33.

3. Janvier A, Khairy M, Kokkotis A, Cormier C, Messmer D, Barrington KJ. Apnea is associated with neurodevelopmental impairment in very low birth weight infants. J Perinatol. 2004; 24:763-8.

4. Martin RJ, Abu-Shaweesh JM, Baird TM. Apnoea of prematurity. Paediatr Respir Rev. 2004;5(Suppl A):S377-82.

5. Pillekamp F, Hermann C, Keller T, von Gontard A, Kribs A, Roth B. Factors influencing apnea and bradycardia of prematurity - implications for neurodevelopment. Neonatology. 2007;91:155-61.

6. Abdel-Hady H, Nasef N, Shabaan AE, Nour I. Caffeine therapy in preterm infants. World J Clin Pediatr. 2015;4:81-93.

7. Henderson-Smart DJ, Steer P. Methylxanthine treatment for apnea in preterm infants. Cochrane Database Syst Rev. 2001:CD000140. https://www.ncbi.nlm.nih.gov/pubmed/11686952.

8. Schmidt B, Roberts RS, Davis P, Doyle LW, Barrington KJ, Ohlsson A, et al. Caffeine therapy for apnea of prematurity. $\mathrm{N}$ Engl J Med. 2006;354:2112-21.

9. Schmidt B, Roberts RS, Davis P, Doyle LW, Barrington KJ, Ohlsson A, et al. Long-term effects of caffeine therapy for apnea of prematurity. N Engl J Med. 2007;357:1893-902.

10. Shenk EE, Bondi DS, Pellerite MM, Sriram S. Evaluation of timing and dosing of caffeine citrate in preterm neonates for the prevention of bronchopulmonary dysplasia. J Pediatr Pharmacol Ther. 2018;23:139-45.
11. Haddad W, Sajous C, Hummel P, Guo R. Discontinuing caffeine in preterm infants at 33-35 weeks corrected gestational age: failure rate and predictive factors. J Neonatal Perinat Med. 2015;8:41-5.

12. Darnall RA, Kattwinkel J, Nattie C, Robinson M. Margin of safety for discharge after apnea in preterm infants. Pediatrics. 1997;100:795-801.

13. American Academy of Pediatrics Committee on Fetus and Newborn. Hospital discharge of the high-risk neonate. Pediatrics. 2008;122:1119-26.

14. Jefferies AL, Canadian Paediatric Society, Fetus and Newborn Committee. Going home: facilitating discharge of the preterm infant. Paediatr Child Health. 2014;19:31-42.

15. Butler TJ, Firestone KS, Grow JL, Kantak AD. Standardizing documentation and the clinical approach to apnea of prematurity reduces length of stay, improves staff satisfaction, and decreases hospital cost. Jt Comm J Qual Patient Saf. 2014;40:263-9.

16. Spitzer AR, Ellsbury DL, Handler D, Clark RH. The Pediatrix BabySteps Data Warehouse and the Pediatrix Quality Steps improvement project system-tools for "meaningful use" in continuous quality improvement. Clin Perinatol. 2010;37:49-70.

17. Olsen IE, Groveman SA, Lawson ML, Clark RH, Zemel BS. New intrauterine growth curves based on United States data. Pediatrics. 2010;125:e214-24.

18. Trembath A, Hornik CP, Clark R, Smith PB, Daniels J, Laughon $\mathrm{M}$, et al. Comparative effectiveness of surfactant preparations in premature infants. J Pediatr. 2013;163:955-60.e1.

19. Eichenwald EC; Committee on Fetus and Newborn, American Academy of Pediatrics. Apnea of prematurity. Pediatrics. 2016; 137:e20153757.

20. Hasibeder WR. Does standardization of critical care work? Curr Opin Crit Care. 2010;16:493-8.

21. Pronovost PJ, Berenholtz SM, Goeschel CA, Needham DM, Sexton JB, Thompson DA, et al. Creating high reliability in health care organizations. Health Serv Res. 2006;41:1599-617.

22. Rozich JD, Howard RJ, Justeson JM, Macken PD, Lindsay ME, Resar RK. Standardization as a mechanism to improve safety in health care. Jt Comm J Qual Saf. 2004;30:5-14.

23. Rhein LM, Dobson NR, Darnall RA, Corwin MJ, Heeren TC, Poets $\mathrm{CF}$, et al. Effects of caffeine on intermittent hypoxia in infants born prematurely: a randomized clinical trial. JAMA Pediatr. 2014;168:250-7.

24. Lodha A, Entz R, Synnes A, Creighton D, Yusuf K, Lapointe A, et al. Early caffeine administration and neurodevelopmental outcomes in preterm infants. Pediatrics. 2019;143:e20181348.

25. Endesfelder S, Weichelt U, Strauss E, Schlor A, Sifringer M, Scheuer $\mathrm{T}$, et al. Neuroprotection by caffeine in hyperoxiainduced neonatal brain injury. Int J Mol Sci. 2017;18:187.

26. National Institutes of Health Consensus Development Conference on infantile apnea and home monitoring, Sept 29 to Oct 1, 1986. Pediatrics. 1987;79:292-9.

27. Finer NN, Higgins R, Kattwinkel J, Martin RJ. Summary proceedings from the apnea-of-prematurity group. Pediatrics. 2006;117:S47-51.

28. Charles BG, Townsend SR, Steer PA, Flenady VJ, Gray PH, Shearman A. Caffeine citrate treatment for extremely premature infants with apnea: population pharmacokinetics, absolute bioavailability, and implications for therapeutic drug monitoring. Ther Drug Monit. 2008;30:709-16.

29. NICHD Neonatal Research Network. Moderately preterm infants with caffeine at home for apnea (MoCHA) trial. ClinicalTrials. gov. 2019. https://clinicaltrials.gov/show/NCT03340727. Accessed Oct 232019. 